\title{
Adult Hemophagocytic Lymphohistiocytosis in Sub-Saharan Area: A Retrospective Study of 26 cases
}

Ngoné Diaba Diack $^{1}$, Baidy Sy Kane ${ }^{2}$, Seynabou Fall ${ }^{3}$, Abibatou Sall ${ }^{4}$, Abdoul Karim Daher ${ }^{5}$, Moustapha Niasse $^{6}$, Nafy Ndiaye ${ }^{1}$, Boundia Djiba ${ }^{2}$, Fatou Samba Ndiaye ${ }^{3}$, Abdoulaye Leye ${ }^{1}$, Abdoulaye Pouye ${ }^{2}$

1. Internal Medicine and Endocrinology, Pikine Teaching Hospital, Dakar, SEN 2. Internal Medicine, Aristide Le Dantec Teaching Hospital, Dakar, SEN 3. Hematology, Dalal Jamm Teaching Hospital, Dakar, SEN 4. Biology Laboratory, Dalal Jamm Teaching Hospital, Dakar, SEN 5. Nephrology, Aristide Le Dantec Teaching Hospital, Dakar, SEN 6. Rheumatology, Aristide Le Dantec Teaching Hospital, Dakar, SEN

Corresponding author: Ngoné Diaba Diack, diackngone@gmail.com

\section{Abstract \\ Introduction and background}

Hemophagocytic lymphohistiocytosis (HLH) is a condition caused by inappropriate stimulation of macrophage cells with hemophagocytosis. This paper aims to describe its diagnostic specifics and etiology and seeks to identify the factors that affect its prognosis in the black African adult population.

\section{Methods}

A retrospective multicentre study was carried out in three medical units in Senegal: Department of Internal Medicine at Pikine Teaching Hospital, and Department of Internal Medicine and Department of Nephrology at Aristide Le Dantec Teaching Hospital; the study covered the period from January 1, 2012 to March 30, 2015. This study included patients aged 18 years and older with a Hemophagocytosis Score (HScore) of $\geqslant 202$ (with probabilities of acquired HLH of $>90 \%$ ). The data was obtained through medical records.

\section{Results}

In total, 26 patient files were included. The average age of the patients was 41 years, with a male-to-female ratio of 2.25:1. Fever and cytopenia were frequent. Other clinical signs included peripheral lymphadenopathy (69.2\%), hepatomegaly (53.8\%), splenomegaly (34.6\%), neurological disorders (34.5\%), and respiratory disorders (15.3\%). Thrombocytosis was noted in three cases. Renal involvement was present in eight patients, with one case of collapsing glomerulopathy. The bone marrow aspirate revealed myelodysplasia in 12 patients. The dominant etiologies of HLH were hematological malignancies and infections. The mortality rate of HLH was $73 \%$. Male gender and non-etiological targeted therapy were significantly associated with mortality. However, the age of $<40$ years in patients and current systemic

Received 02/21/2020 Review began $02 / 24 / 2020$ Review ended 03/10/2020 Published 03/13/2020

\section{๑) Copyright 2020}

Diack et al. This is an open access article distributed under the terms of the

Creative Commons Attribution License CC-BY 4.0., which permits unrestricted use, distribution, and reproduction in any medium, provided the original author and source are credited. disease in some cases were correlated with survival. The use of etoposide had no significant impact on the prognosis of our patients.

\section{Conclusion}

A high rate of male predominance, important central nervous system disorders, myelodysplasia, and paradoxical thrombocytosis were found to be the distinct features of adult HLH in our study population.

Categories: Internal Medicine, Hematology

Keywords: hemophagocytic lymphohistiocytosis, adult, tropical environment

\section{Introduction}

Hemophagocytic lymphohistiocytosis (HLH) involves the inappropriate stimulation of macrophage cells with hemophagocytosis [1]. Generally, it occurs in children with primary immunodeficiency. In adults, HLH often appears as a result of infectious disease, autoimmune disease, or malignancy. HLH is an increasingly recognized disorder in adults [2]. The diagnosis of acquired HLH in adults is often difficult with a broad differential diagnosis. Furthermore, therapeutic decision-making continues to be on the basis of clinical experience and expert opinion [2].

In Sub-Saharan Africa, there have been very few studies on HLH in adult patients [3-5]. The observations from these studies show some clinical and biological atypia that could indicate the specificity of HLH for black African people. Therefore, this study focuses on clinical, biological, and cytological presentations, etiological profile, and outcome factors related to HLH in the black African adult population.

\section{Materials And Methods}

A retrospective multicentre study was carried out in three medical units in Senegal: Department of Internal Medicine at Pikine Teaching Hospital, and Department of Internal Medicine and Department of Nephrology 


\section{Cureus}

at Aristide Le Dantec Teaching Hospital; the study covered the period from January 1, 2012 to March 30, 2015. The data was obtained through medical records.

This study included all patients aged 18 and older who were hospitalized during the study period with a Hemophagocytosis Score (HScore) of $\geqslant 202$ (with probabilities of acquired HLH of $>90 \%$ ) (Figure 1) [6]. Patients with lost or incomplete medical records $(n=3)$ were not included in this study.

\section{Score}

Known underlying immunodepression

Maximal Temperature (C)

Hepatomegaly

Splenomegaly

Lower Hemoglobin level

Lower Leucocytes count

Lower Platelets count

Higher Ferritin level ( $\mathrm{ng} / \mathrm{ml})$

Higher Triglyceride level (mmol/1)

Lower Fibrinogen level $(g / 1)$

Higher SGOT/ASAT level (UI/L)

Hemophagocytosis features on bone marrow aspirate Yes

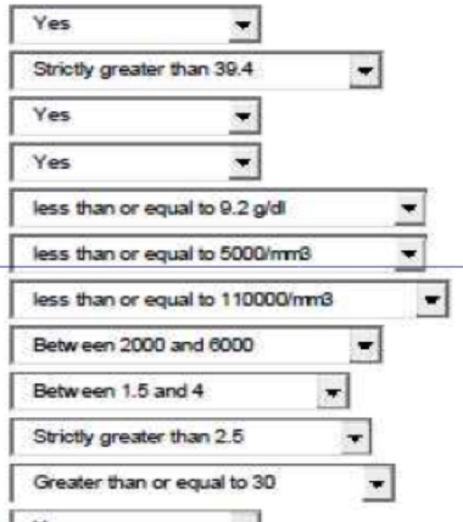

Calculate

HScore

Probability of having HS (\%) 99.8

FIGURE 1: Example of the calculation probabilities of reactive HLH with Hemophagocytosis Score

HLH: hemophagocytic lymphohistiocytosis; SGOT: serum glutamic-oxaloacetic transaminase; HScore: Hemophagocytosis Score; HS: hemophagocytic syndrome

For each included patient, the epidemiological, clinical, biological, cytohistological, therapeutic, and evolutionary data were noted in a record chart. Criteria for the diagnosis of systemic diseases were based on Systemic Lupus International Collaborating Clinics criteria, American College of Rheumatology/European League Against Rheumatism 2013 classification criteria, and American-European 2002 Consensus Group criteria for lupus, systemic scleroderma, and Primary Sjogren's syndrome, respectively [7-9]. We used IBM SPSS Statistics for Windows, Version 20.0 (IBM Corp., Armonk, NY) for statistical analyses. Continuous variables were presented as means and standard deviation. Categoric variables were presented as proportions. For the analytical study, cases classified as "died" were compared with those classified as "survival" (all patients who were alive until the date of the last evaluation in April 2016 were included) using the Fisher exact test for categoric variables. A p-value of $<0.05$ was considered statistically significant.

\section{Results}

\section{Series description}

Overall, 26 medical records were collected (18 men and eight women), with a male-to-female sex ratio of $2.25: 1$. The mean age of patients was $41 \pm 20.2$ years old. Patients younger than 40 years old represented $61.5 \%$ of the study population.

\section{Clinical and biological data}

The different clinical signs recorded in patients included in our series are represented in Table 1 . All patients experienced fever, which was hectic in approximately $75 \%$ of cases. Nine cases of central neurological signs were noted with a normal cytochemical and bacteriological exploration of the cerebrospinal fluid (CSF). Cerebral MRI performed on one of those patients was normal. Regarding the blood count, cytopenia was constant. Anemia was noted in all patients with an average hemoglobin level of $6.1 \mathrm{~g} / \mathrm{dL}$. Autoimmune hemolytic anemia was noted in six patients. Thrombopenia was present in 17 patients and was associated with a hemorrhagic syndrome in five patients. Thrombocytosis was recorded in three patients. The other biological abnormalities recorded in our patients are mentioned in Table 2. 


\section{Cureus}

\begin{tabular}{|l|l|}
\hline Clinical signs & $\mathbf{N}(\%)$ \\
\hline Fever & $26(100)$ \\
Adenopathies & $18(69.2)$ \\
Hepatomegaly & $14(53.8)$ \\
Splenomegaly & $9(34.6)$ \\
Serositis & $10(38.4)$ \\
Neurological signs (conscious disorders, convulsions) & $9(34.5)$ \\
\hline Pulmonary signs (dyspnea, cough, respiratory insufficiency) & $4(15.3)$ \\
\hline
\end{tabular}

\section{TABLE 1: Main clinical signs of HLH recorded in our series}

HLH: hemophagocytic lymphohistiocytosis

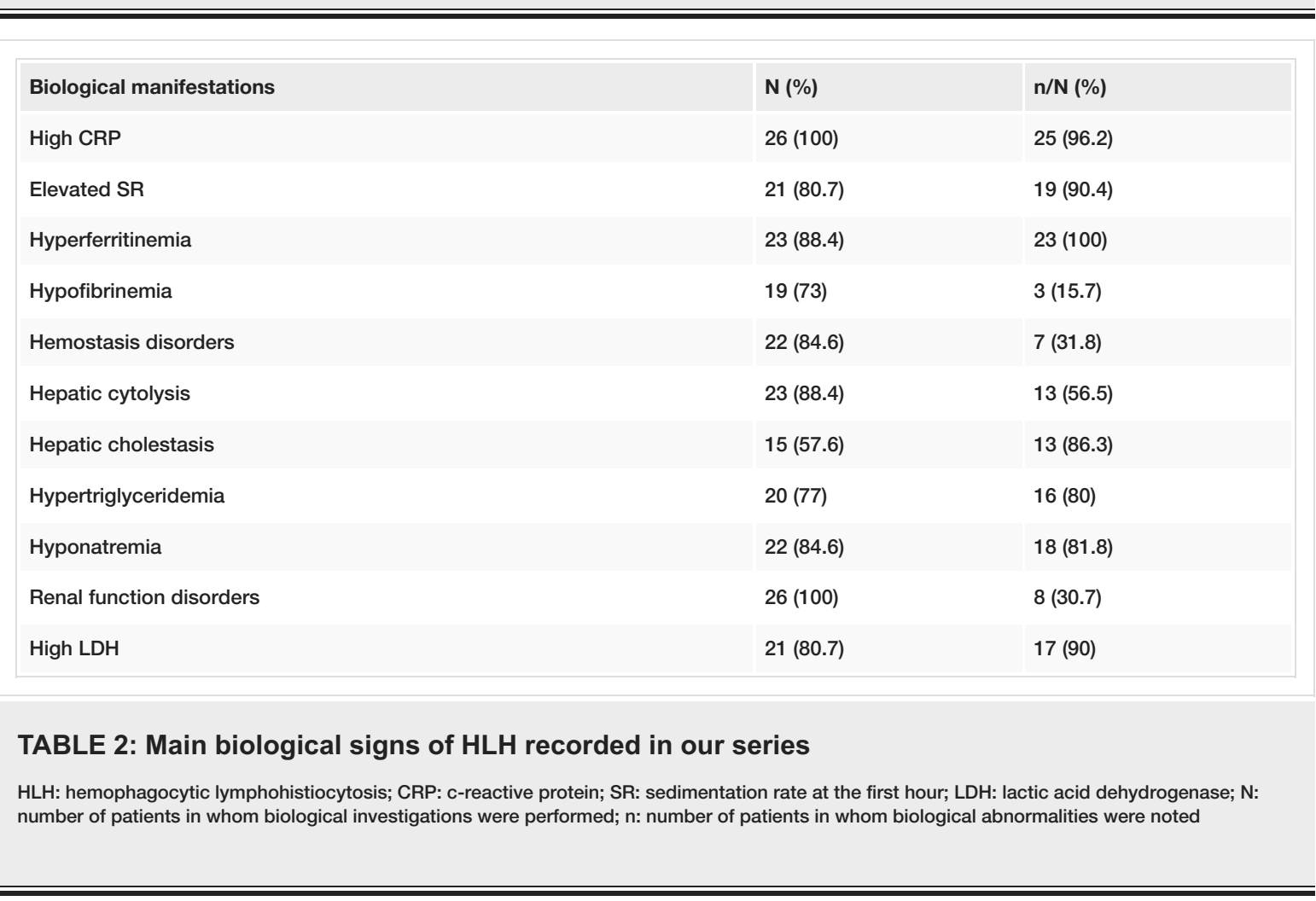

The increases in triglyceride levels, lactic acid dehydrogenase levels, and hepatic enzymes were moderate. Renal impairment markers (e.g., proteinuria, hematuria, aseptic leukocyturia) were recorded in all cases. Acute renal failure was noted in eight patients. Glomerular nephropathy was found and featured an impure nephrotic syndrome or rapidly progressive glomerulonephritis (RPGN) in four patients in our study. The renal histology of one of these patients found a collapsing focal segmental glomerulosclerosis (Figure 2). 


\section{Cureus}

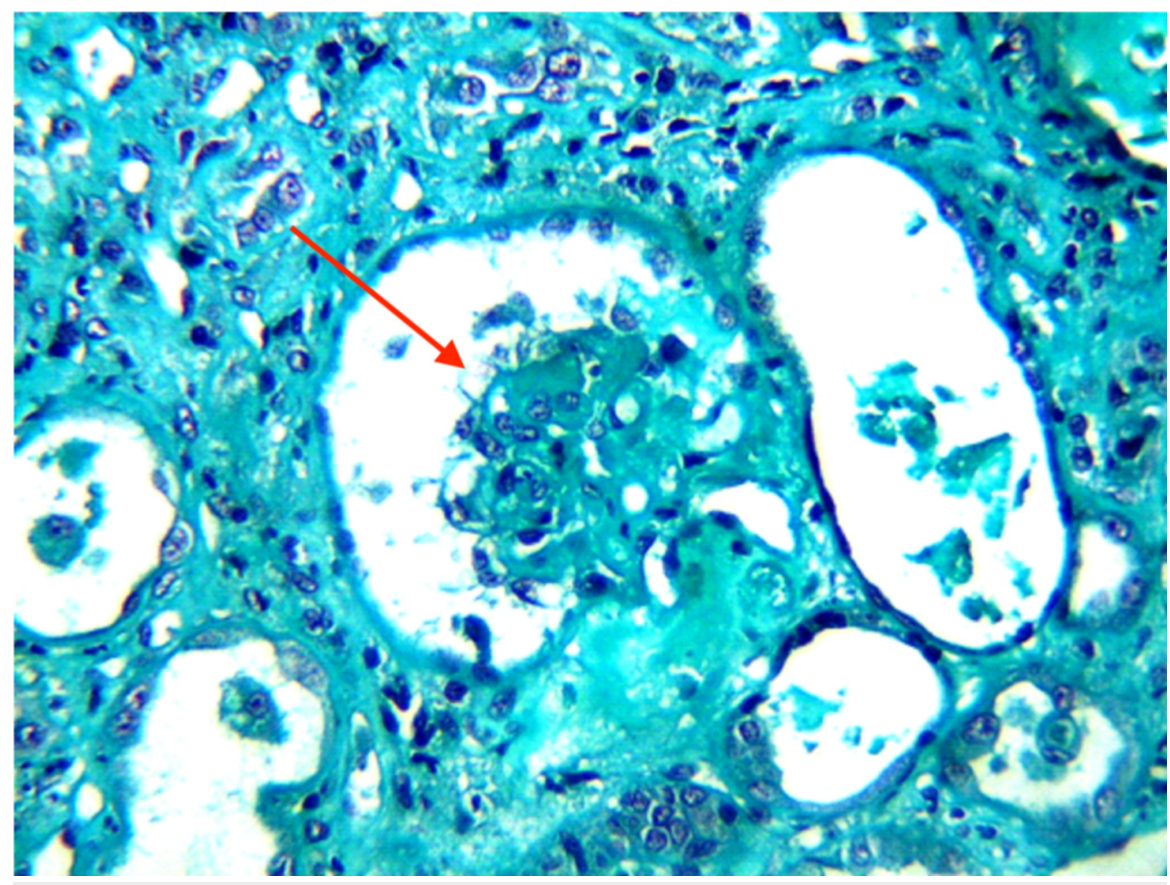

FIGURE 2: Collapsing focal segmental glomerulosclerosis

Renal histology (Masson's trichrome; gross $x$ 200) of a patient that shows a glomerulus (red arrow) in the center of the microphotography characterized by a global collapse of the flocculus surrounded by vacuolized dysmorphic podocytes

\section{Cytological and etiological data}

The myelogram revealed a hemophagocytosis in $76 \%$ of cases (Figure 3) and showed dysmyelopoiesis in 12 patients. The dysmyelopoiesis essentially involved the erythrocyte line with abnormalities such as karyorrhexis (Figure 4), nucleo-cytoplasmic maturation asynchronism, dyskaryosis, binucleated erythroblasts, and basophilic punctuations. The presence of degranulated cells and giant cells was noted. A medullar plasmacytosis was also found in eight patients, outside of a myeloma context.

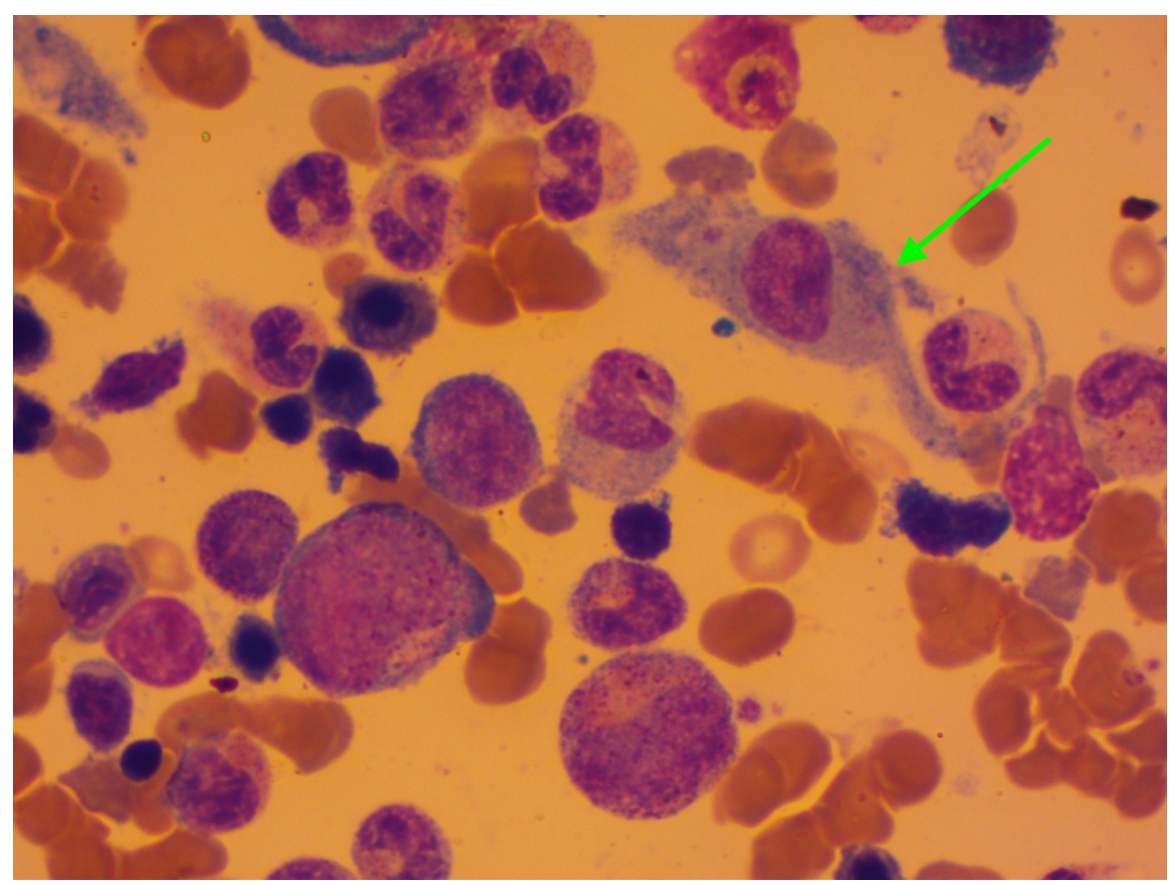

\section{FIGURE 3: Macrophage activation}

Cytology of the medullar fluid showing an activated macrophage (green arrow) engulfing a hematopoietic cell (erythrocyte) 


\section{Cureus}

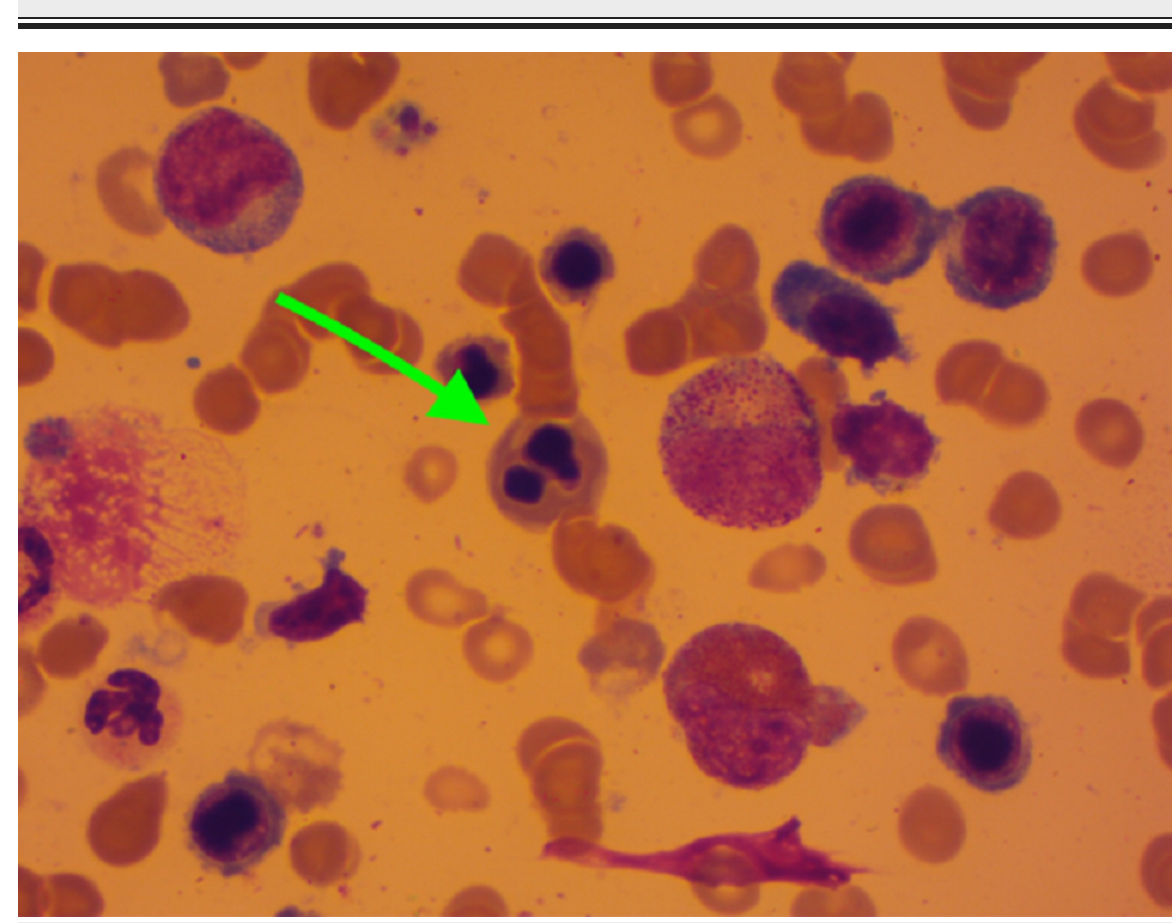

\section{FIGURE 4: Dysmyelopoiesis}

Medullar cytology of a patient showing a dysmyelopoiesis type of karyorrhexis (green arrow)

For the field study, the HLH triggering factor and lymph node biopsy were helpful in eight cases, and the myelogram in two cases. The conditions and/or factors of the patients are noted in Table 3. In two patients, the cause of HLH was not identified. 


\section{Cureus}

\begin{tabular}{|c|c|}
\hline Etiological framework & Main etiologies \\
\hline \multirow{6}{*}{$\begin{array}{l}\text { Hematologic malignancies ( } 11 \\
\text { patients, } 42.3 \%)\end{array}$} & Hodgkin's disease (four cases) \\
\hline & Diffuse large cell B lymphoma (three cases) \\
\hline & T-cell lymphoma \\
\hline & Burkitt’s lymphoma \\
\hline & Acute myeloid leukemia \\
\hline & Multiple myeloma \\
\hline \multirow{4}{*}{ Infections (12 patients, $46.1 \%)$} & $\begin{array}{l}\text { Bacteria: tuberculosis (three cases), atypical mycobacteriosis, pyomyositis, sepsis by } \\
\text { Enterobacter and Burkholderia cepacia }\end{array}$ \\
\hline & Virus: Epstein-Barr virus, hepatitis B, human immunodeficiency virus \\
\hline & Parasite: malaria \\
\hline & Mycosis: systemic aspergillosis \\
\hline \multirow{5}{*}{$\begin{array}{l}\text { Systemic diseases (six patients, } \\
23 \% \text { ) }\end{array}$} & Lupus (two cases) \\
\hline & Scleroderma \\
\hline & Primitive Sjogren's \\
\hline & Microscopic polyangiitis \\
\hline & Multicentric Castleman disease \\
\hline $\begin{array}{l}\text { Primary immunodeficiency (one } \\
\text { patient, } 3.8 \% \text { ) }\end{array}$ & Common variable immunodeficiency \\
\hline $\begin{array}{l}\text { Unfound etiology (two patients, } \\
7.6 \% \text { ) }\end{array}$ & \\
\hline
\end{tabular}

TABLE 3: Main fields and/or triggering factors of adult HLH found in our series HLH: hemophagocytic lymphohistiocytosis

\section{Therapeutic and evolutionary data}

The specific treatment of HLH is found in corticotherapy (bolus of methylprednisolone for three days, followed by oral prednisone). Etoposide (VP-16) was administrated to seven patients. It was associated with corticotherapy in four cases. Specific treatment of the causal pathology (chemotherapy, anti-infectious treatment, immunosuppressors) was introduced in $65.5 \%$ of cases. However, three patients were not under specific treatment.

The mortality rate for HLH was $73.1 \%$. Deaths occurred during hospitalization in $52 \%$ of the cases, and nine patients died after a remission period of approximately 5.8 months. The mean survival rate was 45 days. One case of HLH relapse was noted.

\section{Analytical study}

The study of the influencing outcome factors of HLH in our series is reported in Table 4. We noted that the male gender and the absence of etiological treatment more frequently correlated with mortality. On the other hand, the age of under 40 years and the absence of both hyperfibrinemia and underlying systemic disease were significantly correlated with patient survival. Furthermore, all patients with agranulocytosis ( $\mathrm{p}$ : 0.221) or those without corticotherapy (p: 0.09) had higher mortality. 


\begin{tabular}{|c|c|c|c|c|}
\hline Factors & Patients died ( $\mathrm{n}=19$ ) & Patients alive $(n=7)$ & P-value & OR $(95 \% \mathrm{Cl})$ \\
\hline Age of $<40$ years & 8 & 6 & 0.04 & $0.12(0.01-1.21)$ \\
\hline Male gender & 17 & 1 & 0.000 & $51(3.8-669.4)$ \\
\hline Hemorrhagic syndrome & 2 & 4 & 0.012 & $0.088(0.011-0.71)$ \\
\hline Normal or low fibrinemia & 2 & 3 & 0.04 & $0.11(0.011-1.14)$ \\
\hline Renal function disorder & 7 & 1 & 0.26 & - \\
\hline Myelodysplasia & 9 & 3 & 0.78 & - \\
\hline Hematologic neoplasms & 9 & 1 & 0.07 & - \\
\hline Systemic disease & 1 & 4 & 0.003 & $0.04(0.003-0.51)$ \\
\hline Infections & 4 & 2 & 0.68 & - \\
\hline Corticotherapy & 13 & 7 & 0.09 & - \\
\hline Etoposide & 5 & 2 & 0.90 & - \\
\hline Etiological treatment absence & 11 & 1 & 0.04 & $8.2(0.8-82.6)$ \\
\hline
\end{tabular}

TABLE 4: Influencing outcome factors of HLH in our series

HLH: hemophagocytic lymphohistiocytosis; OR: observed risk; Cl: confidence interval

\section{Discussion}

HLH in adults is an uncommon condition recently labeled as a pathological entity [2]. In Sub-Saharan Africa, this pathology has been the subject of only a few case reports [3-5]. We conducted a three-year retrospective and cross-sectional study to collect 26 observations of adult HLH, undertaking the largest African patient series. In this study, we found that HLH generally affects adult male patients.

A variety of conditions including infection, malignancy, autoimmune disorders, and immunosuppression is associated with HLH in adults [10]. HLH occurred mainly in the presence of underlying hematological malignancies in our patients $[2,11]$. However, the association of acquired HLH with Hodgkin's disease, the main hematological malignancies found in our series, was rare [12]. HLH/autoimmune disease was diagnosed in five of our patients, with two cases of lupus. Regarding these predisposition fields, HLH in adults was mostly triggered by infection [13]. In our series, a documented infection was recorded in approximately half of the cases. They occurred individually or in a predisposition field: hematological malignancies and primary immunodeficiency.

HLH has a life-threatening clinical presentation that affects a wide range of organ systems [2]. An important presence of central neurological disorders was noted in this study. Typically, those neurological signs are more described in HLH in children [10]. However, it is difficult to determine the difference between signs related to HLH and those from the causal pathology. Nevertheless, the clinical assessment findings, as well as the cellularity of CSF, were normal for all those patients. The proportion of renal impairment in our series was high. Some cases of HLH were gathered in a nephrology unit, which could be a source of selection bias. The most specific histological sign noted in our study was collapsing focal segmental glomerulosclerosis. This abnormality was mainly reported in black African patients during acquired HLH [14,15].

Cytopenia was the main biological marker of HLH. Anemia, on the other hand, was profound and permanent in most cases. Thrombocytopenia was the most frequent precocious cytopenia of adult HLH [1,2]. However, this thrombocytopenia was recorded in only $65 \%$ of our patients. Paradoxical thrombocytosis was noted in three of our patients, with two cases of HLH/Hodgkin's disease and one with underlying lymphoma T. The association between HLH and thrombocytosis was rarely reported in the literature [3]. Thrombocytosis occurrence during HLH could be linked to a preexisting chronic inflammation or with underlying hematological malignancies such as Hodgkin's disease, in which the association with a thrombocytosis was reported [16]. Of the medullar hemophagocytosis, the myelogram highlighted dysmyelopoiesis in approximately half of our patients, which could be a cause or consequence of HLH. In fact, exceptional cases of myelodysplastic syndrome (MDS) complicated by HLH were reported [17]. Additionally, some cytological abnormalities mimicking MDS were described during HLH. They might be related to a cytokine rush that led to cellular damages resulting in morphological changes [18]. Although cytogenetic examinations were not performed in our patients, the hypothesis of an underlying MDS is unlikely with a mean age of 34 years and the disappearance of peripheral cytopenias with $42 \%$ having controlled HLH. The dysmyelopoiesis was recorded regardless of the context of vitamin B12 and/or folic acid deficiency. The dysmyelopoiesis, then, could be one more cytological argument for adult HLH diagnosis in our context. 
HLH was also remarkable for the high mortality level in this study. This can be due to the diagnostic delay as well as the presence of underlying hematological malignancies. This analytical study helped identify some prognosis-associated factors of adult HLH. HLH in female patients aged younger than 40 years or with an underlying systemic disease was significantly associated with a good outcome. The absence of etiological treatment was the main poor outcome factor. On the other hand, the use of etoposide was not significantly associated with survival in our patients. Yet, it is presently the first-line treatment of adult HLH [11,19]. However, the efficacy of etoposide is dependent on the underlying etiology of HLH [11].

\section{Conclusions}

We conducted the largest case series in a Sub-Saharan African population. Our study consisted of 26 observations, and our analysis revealed the particularities of adult HLH presentation in our population. The significant presence of neurological signs, myelodysplasia, and paradoxical thrombocytosis were important features of adult HLH in our study population. These features should be considered for the diagnostic assessment and management of HLH patients in tropical areas.

\section{Additional Information \\ Disclosures}

Human subjects: Consent was obtained by all participants in this study. Animal subjects: All authors have confirmed that this study did not involve animal subjects or tissue. Conflicts of interest: In compliance with the ICMJE uniform disclosure form, all authors declare the following: Payment/services info: All authors have declared that no financial support was received from any organization for the submitted work. Financial relationships: All authors have declared that they have no financial relationships at present or within the previous three years with any organizations that might have an interest in the submitted work. Other relationships: All authors have declared that there are no other relationships or activities that could appear to have influenced the submitted work.

\section{References}

1. Al-Samkari H, Berliner N: Hemophagocytic lymphohistiocytosis. Annu Rev Pathol. 2018, 13:27-49. 10.1146/annurev-pathol-020117-043625

2. Ramos-Casals M, Brito-Zerón P, López-Guillermo A, Khamashta M, Bosch X: Adult haemophagocytic syndrome. Lancet. 2014, 383:1503-1516. 10.1016/S0140-6736(13)61048-X

3. Lekpa FK, Ndongo S, Fall S, Pouye A, Ka MM, Moreira-Diop T: Thrombocytosis in a macrophage activation syndrome complicating systemic lupus erythematosus. (Article in French). Pan Afr Med J. 2014, 19:11. Accessed: March 13, 2020: https://www.ncbi.nlm.nih.gov/pubmed/25584123. 10.11604/pamj.2014.19.11.2071

4. Niang A, Diallo S, Ka MM, Pouye A, Diop S, Ndongo S, Diop TM: Hemophagocytic syndrome complicating adult's seropositive rheumatoid arthritis. (Article in French). Rev Med Interne. 2004, 25:826-828. 10.1016/j.revmed.2004.07.008

5. Kane BS, Niasse M, Faye A, et al.: Macrophage activation syndrome, a rare complication of primary Sjögren's syndrome: a case report. J Med Case Rep. 2019, 13:309. Accessed: March 13, 2020: https://www.researchgate.net/publication/336585557_Macrophage_activation_syndrome_a_rare_complication_of_primary_Sic $10.1186 / \mathrm{s} 13256-019-2252-\mathrm{z}$

6. Fardet L, Galicier L, Lambotte O, et al.: Development and validation of the HScore, a score for the diagnosis of reactive hemophagocytic syndrome. Arthritis Rheumatol. 2014, 66:2613-2620. 10.1002/art.38690

7. Petri M, Orbai AM, Alarcón GS, et al.: Derivation and validation of the Systemic Lupus International Collaborating Clinics classification criteria for systemic lupus erythematosus. Arthritis Rheum. 2012, 64:2677-2686. 10.1002/art.34473

8. van den Hoogen F, Khanna D, Fransen J, et al.: 2013 classification criteria for systemic sclerosis: an American College of Rheumatology/European League Against Rheumatism collaborative initiative. Arthritis Rheum. 2013, 65:2737-2747. 10.1002/art.38098

9. Vitali C, Bombardieri S, Jonsson R, et al.: Classification criteria for Sjögren's syndrome: a revised version of the European criteria proposed by the American-European Consensus Group. Ann XRheum Dis. 2002, 61:554-558. 10.1136/ard.61.6.554

10. Campo M, Berliner N: Hemophagocytic lymphohistiocytosis in adults. Hematol Oncol Clin North Am. 2015, 29:915-925. 10.1016/j.hoc.2015.06.009

11. Rivière S, Galicier L, Coppo P, Marzac C, Aumont C, Lambotte O, Fardet L: Reactive hemophagocytic syndrome in adults: a retrospective analysis of 162 patients. Am J Med. 2014, 127:1118-1125. 10.1016/j.amjmed.2014.04.034

12. Lehmberg K, Nichols KE, Henter JI, et al.: Consensus recommendations for the diagnosis and management of hemophagocytic lymphohistiocytosis associated with malignancies. Haematologica. 2015, 100:997-1004. 10.3324/haematol.2015.123562

13. Bindra BS, Garcia de de Jesus K, Cisneros O, Jorge VM, Kaur H: Hemophagocytic lymphohistiocytosis: management and special consideration in human Immunodeficiency virus positive patients with immune reconstitution syndrome. Cureus. 2019, 11:e5402. Accessed: March 13, 2020: https://www.cureus.com/articles/22174-hemophagocytic-lymphohistiocytosis-management-and-specialconsideration-in-huma.... 10.7759/cureus.5402

14. Thaunat O, Delahousse M, Fakhouri F, Martinez F, Stephan JL, Noël LH, Karras A: Nephrotic syndrome associated with hemophagocytic syndrome. Kidney Int. 2006, 69:1892-1898. 10.1038/sj.ki.5000352

15. Niang A, Niang SE, Ka el HF, Ka MM, Diouf B: Collapsing glomerulopathy and haemophagocytic syndrome related to malaria: a case report. Nephrol Dial Transplant. 2008, 23:3359-3361. 10.1093/ndt/gfn427

16. Dwilewicz-Trojaczek J, Wieczorek J: Thrombocytosis in patients with non-Hodgkin's lymphomas and Hodgkin's disease. (Article in Polish). Pol Arch Med Wewn. 1997, 98:117-121. 


\section{Cureus}

17. Tsuji T, Yamasaki H, Arima N, Tsuda H: Hemophagocytic lymphohistiocytosis associated with myelodysplastic syndromes. Int J Hematol. 2010, 92:547-549. 10.1007/s12185-010-0661-2

18. Imashuku S, Kitazawa K, Ishii M, et al.: Bone marrow changes mimicking myelodysplasia in patients with hemophagocytic lymphohistiocytosis. Int J hematol. 2000, 72:353-357.

19. Imashuku S, Kuriyama K, Teramura T, et al.: Requirement for etoposide in the treatment of Epstein-Barr virus-associated hemophagocytic lymphohistiocytosis. J Clin Oncol. 2001, 19:2665-2673.

10.1200/JCO.2001.19.10.2665 